
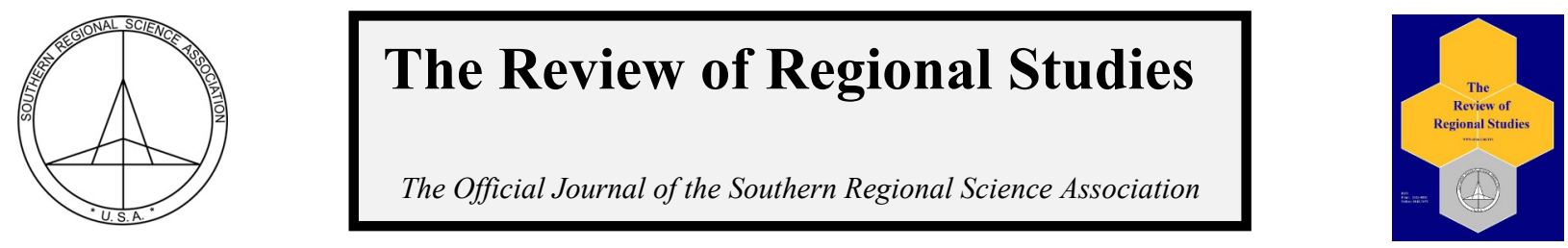

Presidential Address-Mobile, Alabama March 28, 2015

$54^{\text {th }}$ Meetings of the Southern Regional Science Association:

\title{
Is Regional Science the Embodiment of the Engaged University?*
}

\author{
Steven C. Deller \\ Department of Agricultual and Applied Economics, University of Wisconsin-Madison, USA
}

\begin{abstract}
In this Presidential Address, the author explores the role of the "Engaged University." He argues that the relevance of work in regional science is an exemplar for activities that enable a university to engage with real-world issues that have an impact on society.
\end{abstract}

Keywords: regional science, university engagement

JEL Codes: R0

\section{INTRODUCTION}

Presidential addresses are often an opportunity to reflect on the Association and the field, or discipline, of regional science. A natural starting point is to review Andy Isserman's now classic address to the Southern Regional Science Association entitled "Lost in Space? On the History, Status, and Future of Regional Science" (1993) and his follow-up piece "The History, Status, and Future of Regional Science: An American Perspective" (1995) along with his SRSA's 2010 Fellows Address. In those essays, Andy challenged us to reflect on Walter Isard's original vision. With Andy's coordination there were any number of reflective pieces on regional science, particularly the special issue of the International Regional Science Review entitled "Regional Science at Forty" (1995).

Andy's untimely death spurred his colleagues and friends to reflect on his contributions to regional science and to revisit the challenges that he laid down in his assessments of the field. Two examples include Luc Anselin's (2013) “Andy Isserman's Regional Science” and Ann Markusen's (2015) "Problem-driven Research in Regional Science" (2015). These reflective exercises made it clear that regional science, as a field of study or a discipline, has two audiences for its work: internal and external.

Internal audiences tend to emphasize elegant theories, publications in the top journals, and general acceptance within the parent disciplines. Within the ivory tower of the academy this often translated into the creation of departments of regional science. Here many reached the false

\footnotetext{
${ }^{*}$ The written version of this address has benefited from the very helpful comments of Michael Lahr, Judith Stallmann, and Norm Walzer. The opinions expressed are solely those of the author.

Deller is Professor of Agricultural and Applied Economics at University of Wisconsin-Madison/Extension, Madison, WI.

Email: scdeller@wisc.edu
}

(C) Southern Regional Science Association 2015.

ISSN 1553-0892, 0048-749X (online)

www.srsa.org/rrs 
conclusion that regional science has fallen short of Walter Isard's dream. This benchmark of success is too narrow and a wrong way to think about his concept. In fact, the ideas of space and geography are now more widely discussed in the field's parent disciplines. Indeed, Paul Krugman won the Nobel Prize in Economics "for his analysis of trade patterns and location of economic activity" and contributions to international trade, economic geography, and regional economics. Clearly Walter Isard's dream may already be fulfilled; we are not "lost in space."

The external audience was particularly close to Andy's vision of regional science. We can think of two simple metrics of our success with external audiences: (1) are our students in demand and (2) is our work influencing policies? I would argue that the answer to the first question is a resounding "yes!" Our students, particularly Master's students, are highly coveted by governmental agencies at the federal, state, and local levels, private consulting businesses, and within academia. It is more difficult to answer the second question "Is our work influencing policy?" The demand for public policy analysis is strong as evidenced by the rapid growth in the number of public policy schools such as the LaFollette School of Public Policy at the University of Wisconsin-Madison and the Truman School of Public Affairs at the University of Missouri. Andy Isserman referred to this as an "opportunity lost" for regional science. In addition, I am reminded of Martin Shields's presidential symposium for the Mid-Continent Regional Science Association 2002 annual meeting entitled "Regional Scientists are Talking - Is Anybody Listening?” Michael Lahr (2009) rephrased the question as “... whether regional science has lost its seat at the policy table."

The answer to Shields's question is "yes, people are listening," but from Lahr's perspective, we may be at the table, but it looks like the kiddy table to me. Even if we are at the adult table, we are involved in only a small fraction of the conversation. We can do better. To help drive this home, Ed Feser and Andy Isserman organized a special issue of the Journal of Regional Analysis and Policy (2007), as a tribute to Ron Shaffer. It focused on documenting how regional scientists have informed rural development policy. A total of 20 short essays were published ranging from Ann Markusen's work on the arts to Dave Marcouiller's work on rural tourism to Michael Ward's work on rural telecommunication to Judy Stallmann's work on state and local government tax and expenditure limitations. The problem is that while some of these essays described how the work of regional scientists impacted policy, most described how or why the work could and should impact policy.

As I was rereading Isserman's work and reflecting on the state of regional science, something happened in Wisconsin that made me rethink his reflective work in a different light. The University of Wisconsin System has a codified mission statement that reads:

36.01 (2) The mission of the system is to develop human resources to discover and disseminate knowledge, to extend knowledge and its application beyond the boundaries of its campuses and to serve and stimulate society by developing in students heightened intellectual, cultural, and humane sensitivities; scientific, professional, and technological expertise; and a sense of value and purpose. Inherent in this broad mission are methods of instruction, research, extended training and public service designed to educate people

(C) Southern Regional Science Association 2015. 
and improve the human condition. Basic to every purpose of the system is the search for truth. ${ }^{1}$

As part of this mission the University of Wisconsin - Madison has embraced what is referred to as the "Wisconsin Idea." UW President Charles Van Hise declared in 1904 that he would "never be content until the beneficent influence of the university reaches every family in the state." In essence "the boundaries of the University are the boundaries of state." During Wisconsin's progressive period in the early 1900s, state governors and legislators regularly turned to the faculty of the University to help craft policy. Examples include the creation of workers compensation insurance, worker safety regulations, and the formation of cooperatives as a business model, among others. Indeed, the original authors of the Social Security Act can be traced back to economic faculty members at the UW-Madison. Clearly policy makers turned to the experts at the University to help think about and craft policy.

In 2015 Wisconsin Governor Walker suggested that we change the mission statement of the University System to read:

36.01 (2) The mission of the system is to develop human resources to meet the state's workforce needs, to discover and disseminate knowledge, its application beyond the boundaries of its campuses and to serve and stimulate society by developing develop in students heightened intellectual, cultural, and humane sensitivities, scientific, professional and technological expertise, and a sense of purpose. Inherent in this broad mission are methods of instruction, research, extended training and public service designed to educate people and improve the human condition. Basic

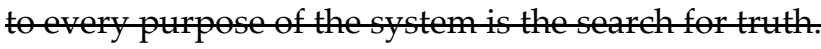

There are three major changes here: (1) the movement to the state's workforce needs, (2) the removal of the core values of the Wisconsin Idea, and (3) the removal of the "search for truth." The reaction to the proposed changes was swift and strong. The movement to focusing on the state's workforce needs was interpreted as a movement away from liberal arts education to more of a technical school model. The removal of the Wisconsin Idea was interpreted as a means of building a wall between the University and the residents of Wisconsin. Finally, the removal of the "search for truth" was viewed as an attempt to "muzzle" the University from challenging policy ideas. The backlash across Wisconsin was so strong and negative to the proposed changes that the next day Walker tweeted "The Wisconsin Idea will continue to thrive. The final version of budget will fix drafting error-Mission statement will include WI Idea."

While there is still debate within Wisconsin about whether this was truly a drafting error or an attempt to undermine the University (indeed, the Milwaukee Journal Sentinel's PolitiFacts concluded that the "drafting error" excuse rated a "pants on fire") it raises questions that should concern us in regional science. Are regional scientists becoming irrelevant in today's policy environment? Should we isolate ourselves in the ivory tower and produce elegant theories that only a handful of us can read and understand? Should we redouble our efforts to make our work policy relevant? I argue that we need to redouble our efforts on policy work; as long as we build our analyses on sound research-based principles our work should rise above short-term political noise.

\footnotetext{
1 See https://www.wisconsin.edu/regents/policies/the-university-of-wisconsin-system-mission/ for the latest version of the mission statement.
} 


\section{THE ENGAGED UNIVERSITY}

Within the U.S., a major reorientation of higher education away from studying the classics or teacher preparation and toward thinking about contemporary public issues came with the passage of the Morrill Act of 1862 and the establishment of the land-grant colleges. ${ }^{2}$ The idea behind the land-grant system of colleges was to open access to higher education to a wider range of citizens and to promote research and professional development for industry. At the time, industry was predominately agriculture mixed with a modest but growing manufacturing sector. Farmers would identify specific problems or needs for efficiency gains, and the experts at the new land-grants would conduct research through scientific inquiry to gain answers. This "tech transfer" model set the stage for how colleges and universities would engage the needs of the citizenry: academics are the experts and have research based answers to citizens' questions.

Within Wisconsin, this notion of the engaged university came under the title of the Wisconsin Idea. University of Wisconsin President Charles Van Hise declared in a 1904 speech that, "I shall never be content until the beneficent influence of the University reaches every home in the state." As president from 1903 to 1918, Van Hise saw that vision carried out by creating the university's extension division, which oversaw summer courses and other programs that brought university knowledge directly to state citizens. The establishment of the Wisconsin extension division served as the model of the USDA Cooperative Extension Services which was established nationally in 1914 with the Smith Lever Act. This rich tradition of outreach education via extension at Wisconsin serves as a backdrop to the strong negative reaction to Governor Walker's proposal to remove the Wisconsin Idea from the core mission of the University.

Over time, these institutions of higher education grew into collections of different colleges, taking the form of modern universities. The connection to the residents of the state became strained. As noted by Mayfield (2001, p. 235) "In research, the dominant fraction still uses the traditional academic model of autonomous faculty conducting pure research. Such researchers derive their questions and methods from their disciplines, rather than including community interests."

Part of what drives this is the incentive mechanisms within institutions of higher education. What has more "value" within a university setting, the development of a grand conceptual piece published in a top-tiered journal that over time may have 100 citations or a well-crafted policy paper that does not stand a chance of being published in an academic journal but alters how a state government spends millions of dollars on a particular policy? Alternatively, which carries weight with peers, an invitation to present a seminar at a prestigious university or being asked to testify before a state legislative committee?

The answer to questions like these has placed public universities in particular in a very difficult position. As noted by Bridger and Alter (2006, p. 163) "America's universitiesespecially our public universities - are facing unprecedented scrutiny and criticism. Faculty are faulted for pursuing research at the expense of teaching, for conducting research that is disconnected from real-world problems, and for worrying more about personal advancement than service to the community."

\footnotetext{
${ }^{2}$ Many schools that became land grants were originally teaching colleges and saw the call for land grant status as a means to significantly broaden their missions.
} 
Wisconsin Assembly Speaker Robin Vos, who agreed with Governor Walker's proposed changes to the University's mission statement until he was against it, stated in November 2014 "[o]f course I want research, but I want research done in a way that focuses on growing our economy, not on the ancient mating of whatever. So we want to try to have priorities that are focused on growing our economy." To me, this sounds like the type of research many regional scientists undertake in both theoretical and empirical or more policy-oriented settings even if in the role of a consultant.

Yet, we as academics seem set on shooting ourselves in our collective foot. In March of 2015 when the University mission statement was being debated, local journalist Chris Rickert reacted to a press release issued by the University on a piece of research:

I and the writers of a couple of rather unkind letters to the editor had the same reaction to a recent bit of news out of UW-Madison concerning music preferences among man's (and woman's) second-best friend: A study on cat music?! we sputtered. This is what they're using our tax dollars for?! To figure out whether cats are more into smooth jazz or gansta rap?!

What was ignored by the media and the political discussions was that the journal article published was by an undergraduate with the guidance of a faculty member. That article was a major reason the student was accepted into a very prestigious graduate program in physiology. The press release by the university was aimed at highlighting undergraduate research but the media and general public focused on the research topic.

The general public perception that institutions of higher education spend limited public resources on esoteric research, such as which type of music cats prefer listening to or the "ancient mating of whatever," has resulted in a general decline in public tax dollars going to higher education. While public tax dollars devoted to higher education has ebbed and flowed with the fiscal conditions of state governments, over the past 14 years there has been a general erosion of that support. In constant 2013 dollars, education appropriations per full-time equivalent student have declined from a peak of \$8,470 in 2001 to \$6,105 in 2013.

These trends raise questions that should concern us in regional science. Are regional scientists becoming irrelevant in today's policy environment? Or in the words of Martin Shields "regional scientists are talking but is anyone listening?" Again, should regional scientists remain in the ivory tower of academia or should we redouble our efforts to make our work policy relevant? I concur with Isserman and argue that we need to redouble our efforts on relevant policy work. Rather than shrinking away to the ivory tower and becoming even less relevant to the general public, we should embrace the challenge of Wisconsin Assembly Speaker Robin Vos and conduct relevant research that helps people understand the economic and social issues that affect their communities. This is not to say we abandon rigorous theoretical and empirical work, but rather refocus on bridging the insights gained from that work into policy discussions. In addition, the questions and issues raised in those policy discussions need to flow back and inform the theoretical research agenda.

Indeed, I argue that the work of regional scientists is the embodiment of the engaged university. Here Ellison and Eatman (2008, p. iv) state:

Publicly engaged academic work is scholarly or creative activity integral to a faculty member's academic area. It encompasses different forms of making knowledge about, for, and with diverse publics and communities. Through a coherent, purposeful sequence 
of activities, it contributes to the public good and yields artifacts of public and intellectual value.

In a similar vein the Carnegie Foundation (2005) states that "University Engagement describes the collaboration between higher education institutions and their larger communities (local, regional/state, national, global) for the mutually beneficial exchange of knowledge and resources in a context of partnership and reciprocity."

Many U.S. public universities have embraced the notion of the engaged university. One such example is demonstrated in the mission statement of Michigan State University (emphasis added)

Outreach is a form of scholarship that cuts across teaching, research and service. It involves generating, transmitting, applying and preserving knowledge for the direct benefit of external audiences in ways that are consistent with university and unit missions.

and another from Ohio State University (emphasis added):

Outreach and Engagement is a meaningful and mutually beneficial collaboration with partners in education, business, public and social service. It represents that aspect of teaching that enables learning beyond the campus walls; that aspect of research that makes what we discover useful beyond the academic community; and that aspect of service that directly benefits the public.

Pennsylvania State University introduces the importance of interdisciplinary work, which I argue is second nature to regional scientists (emphasis added):

Penn State's vision of engagement involves the integration of teach, research, and service to enable its faculty, staff, and students to address pressing societal challenges faced by its communities. This integration is intended to inform and invigorate each of the missions, while simultaneously encouraging faculty to cut across disciplinary lines to work reciprocally and in partnership with communities on problems of mutual concern. Fundamental to this vision is that scholarship represents a core value and output of the University, and should be evidenced and evaluated in all engagement activities.

The University of Wisconsin (not so arbitrarily selected here) talks in terms of the scholarship of outreach educational efforts (emphasis added):

Outreach scholarship is conducted in all areas of the university's mission: teaching, research, and service. It involves the creation, integration and application of knowledge for the direct benefit of external audiences. Outreach scholarship is regarded to be of high quality when there is evidence that it has resulted in significant outcomes.

The point is that the engaged university and outreach education exist for more than simply making research studies available to the general public. As with resident instruction, there exists a difficulty in accomplishing this goal: how does one present complex ideas and research insights about a particular issue to a non-academic audience? I will return to this important question later. The University of Alabama talks in terms of community-engaged scholarship (emphasis added):

...we define the scholarship of engagement as a partnership that joins together the specialized knowledge of the campus with the practical knowledge of the public to solve 
critical problems of interest to both. The concept of community-university engaged scholarship has emerged over the past two decades as part of the continuing dialogue on the nature of knowledge and the role of academic institutions in society. The goals of community-engaged scholarship are the generation, exchange, and application of mutually beneficial and socially useful knowledge and practices developed through active partnerships between the academy and the community.

The University of Georgia embraces the engaged university perhaps most directly: “...enhances quality of life in Georgia by applying the knowledge of the University to the state's evolving economic, social, and community needs."3

A not-so-evident key in most if not all of these mission statements is the two-way nature of the engagement. Many universities and faculty see the engagement as a one-way street where the faculty or researcher is the dispenser of knowledge along the lines of technology transfer: the community has a question and I have the answer. As I argue later, in some cases this is an appropriate role, but in most cases it is not: as the espousers of knowledge should we not also yearn to learn from those outside the academy? The question of the two-way nature of the engaged university is who sets the research agenda? Is it a professor and student picking some interesting, but somewhat esoteric, topic, such as the music preferences of cats, or is the research informed by the issues affecting the community? Should the research program of the regional scientist ebb and flow with the issues affecting the larger public community? Some look at my research record and conclude that I am scattered and all over the board: a mile wide and an inch deep. I plead guilty for two reasons. First, my research program does indeed ebb and flow with the issues facing Wisconsin and rural communities. Second, as there are so many fascinating research and policy questions, how can one possibly narrow the agenda to just a handful of topics?

When I looked through the program for this year's (2015) SRSA meetings, I saw a wide range of studies that perfectly match the challenge laid down by Wisconsin Assembly Speaker Robin Vos and outlined by the mission statements of so many public universities. Examples include "The Role of Investment in Education in Economic Development: An Empirical Assessment" by Zimmerman and Gebremedhin, "Strategic Interaction and Economic Development Incentive Policies: Evidence from U.S. States" by Wang, or "Do Federal Incentive Programs Increase Innovation and Entrepreneurship in Economically Disadvantaged Areas?" by Ross, Harger and Stephens.

The challenge for regional scientists is that we, I believe, all want our work to be relevant whether it is developed with elegant formal mathematics, via convincing discourse through use of solid case studies or by means of statistical inference. Again, as long as we build our analyses on sound research-based principles including solid theoretical foundations and rigorous empirical

\footnotetext{
${ }^{3}$ I readily acknowledge a bias here in referencing land grant universities and R1 research universities. There are numerous cases where second-tier universities, those that tend to be predominately teaching institutions, have embraced similar core values related to outreach education and policy relevant applied research. Western Illinois University, my undergraduate home, states as a core value: "We serve as a resource for and stimulus to educational, cultural, environmental, community and economic development in our region and well beyond it." The University of Wisconsin-Whitewater has eight parts to its mission including "To serve as a regional cultural and economic resource center through its service initiatives." While undergraduate instruction remains the core of these universities, they have embraced that outreach beyond the campus into the larger regional community which is vital to not only the vibrancy of the universities themselves but to the broader communities that support them.
} 
analysis, our work should rise above short-term political noise and have a lasting impact on society.

Many universities have embraced and promoted the notion of engaged work and regional scientists could and should be at the tip of the engagement spear. On the other hand, the university institutional reward structure is stacked against this type of work. Ann Markusen (2015, p. 17) correctly observes "Problem-driven research may be more difficult and risky than methods-driven research. ...Universities encourage us to publish in highly ranked journals and make substantive contributions to theory or analytical tools, pressures especially strong in formative career stages." Here she equates problem-driven research with greater policy relevance or with issues identified in the state or community as a problem that needs to be addressed and method-driven research as purer academic research that may or may not have direct policy implications at the moment. Michael Lahr (2009, p. 496) succinctly stated "[t]o our dismay, however, results of many policy projects are not publishable."

Returning to my question posed earlier, what has more "value" within a university setting, the development of a high quality journal article or a well-crafted policy paper that helps steer effective public policies? To the typical politician who directly influences state budgets for public universities it is clearly the latter; but to tenuring and promotion committees more often than not it is the academic journal article that meets the criteria. The challenge, and this is something that I believe regional scientists have mastered, is how to accomplish both. How do we craft and deliver effective policy papers that meet the needs of policy makers and yet is able to stand the test of peer review (i.e., publishing in the academic literature)? Too often academics craft the problem as an all or nothing game. As a group, we regional scientists generally seem to be able to effectively strike the happy medium between the two extremes. We feel comfortable in our policy analysis and discussions because we have pushed the envelope of theoretical and empirical analysis but we understand and appreciate the balance.

\section{HOW DO WE MOVE FORWARD?}

If we return to the reflections of Isserman I think we can build a framework to move forward. Luc Anselin (2013) suggested that Andy's reflections can be summarized along five themes or "bullet points": (1) regional science as neither regional nor science, (2) applied problem-oriented regional science, (3) empiricism, (4) regional scientists' need to go outdoors more, and (5) interdisciplinary research. While Anselin and I could debate nuisances of Isserman's reflective work and Anselin might disagree with my interpretations, these themes capture the engaged nature of regional science work.

There is as much art in regional science analysis as there is science. For example, we can build complex regional simulation models such as IMPLAN, REMI, or Tom Johnson's COMPASS models but the construction of these models and the interpretations of the resulting analysis require a degree of art. Does "our gut" tell us if the analysis is reasonable? As a rule we should question "big multipliers" but how big is "big"? If we modify the assumptions of our models and we get different policy results, which assumptions are the most reasonable for the situation at hand? One could say that this "insight" comes with experience, but in the end judgment calls are required. This is true of any applied work and helps explain why we tend to say "but on the other hand."

(C) Southern Regional Science Association 2015. 
I think regional scientists are drawn to applied problems, problems that affect people and businesses within their community. We are drawn to questions like "why do states continue to offer tax incentives to recruit businesses when we "know" such incentives generally do not work?" Or more generally, "why do some communities, or regions, appear to be prosperous while others struggle, stagnate, and decline?" What draws me to the Southern Regional Science Association is that it is a self-selected community of scholars who are interested in using the most rigorous methods possible in order to gain insights into these questions. Again, for me regional science and the Southern Regional Science Association is the embodiment of that twoway road of the engaged university.

Our work within regional science is based on real, not simulated, data that is convenient to demonstrate a new method or theory. Indeed, regional scientists spend a significant amount of time worrying about data quality. We worry because we want our analysis to be as accurate as possible since in our hearts we hope the analysis can meaningfully influence policy. If our data are poor or our analysis is sloppy, then we run the risk of losing creditability with policy makers and the general public.

Saying that regional scientists need to go outdoors more often is a pleasant way of challenging us to become more engaged in the discussions taking place within the state and communities. If we are the embodiment of the engaged university then we are listening to the issues with which communities are struggling. If those issues are to inform our research agenda, then we must listen to and learn from the public; this requires leaving the comfort of our offices and going outdoors more often. In other words, to be relevant we must leave the ivory tower and listen.

I have found that if I am to truly understand what is happening at the community or regional level I must take an interdisciplinary perspective. If I am to understand how a community truly functions, I must have a fundamental understanding of social and political dynamics. Indeed, this interdisciplinary perspective is at the heart of Isard's original vision of regional science. Regional science is a place where economists, sociologists, and political scientists, to name a few, can come together and learn from each other. This is our strength. Returning to the observations of Ann Markusen, the institutional rules of academia make truly interdisciplinary research difficult. Increasingly I publish much of my work in public administration as well as sociology journals, and my economist colleagues within my department have a very difficult time relating to that body of work. Some department colleagues have asked why I do not publish more in mainstream economics journals: my response is they are not the best outlets or audiences for the work that is relevant to Wisconsin and/or the region.

The challenge is threefold: (1) is our research addressing issues that are relevant to the broader community, (2) can that research add to the academic literature, and (3) can it be disseminated in a manner that policy makers can understand and appreciate? To help address the last question we need to ask ourselves about our role in public policy discussions. Do we follow the expert model, where we tell policy makers what to do? Or are we educators where we lay out policy options with the benefits and costs clearly identified? The second role is more difficult, but is typically much more effective in influencing policy. As an outreach or extension specialist, I view my core role as "helping communities make more informed decisions." In playing this role I bring research-based information to the policy-making table and give concerned citizens the information they need to make an informed decision. Helping communities think through or facilitating community discussions around the relevant issues and possible policy options 
provides for more sustainable action than providing a consultant's report with "the answer." If it is their decision, as opposed to an expert telling them what to do, the sustainability of action is much stronger. ${ }^{4}$ Paraphrasing an old proverb, they have learned to fish. Policies and strategic action should reflect the specific characteristics of each particular community: what works in one community or region may not transfer well to another. Local residents are in the best position to make the relevant judgments, not an outside expert who knows little of the local socio-political setting. The inability to apply a cookie-cutter approach is quite frustrating to most communities, not to mention state and even federal policy makers who are looking for a quick fix. Primarily it requires them to think for themselves. I have had state legislators tell me on more than one occasion we need more one-handed economists. ${ }^{5}$ It seems that sometimes they want the "expert" to tell them what to do because making decisions around complex issues is difficult; as long as the answer coincides with their pre-held political beliefs. Unfortunately, many elected officials will "shop around" experts till they have the expert with the answer they want.

But what are some specific tangible take-aways that could help regional scientists become more effective in engaging policy makers and the general public? In addition to my own experiences in outreach or extension research and education, there are several regional scientists who have put considerable thought into this including the work of Isserman referenced above, the Macke, Hirasuna, Fluharty, and Shields Mid-Continent Regional Science Association Presidential Symposium (2003), Lahr (2009), Hird (2009), Markusen (2015) and Hirasuna and Hansen (2009). Regional scientists must be sensitive to the facts about policy makers: (1) they are not "policy wonks" and are interested in executive summaries; (2) their schedules are busy and they are working on multiple issues at once; (3) they have pre-held beliefs and must answer to their constituents; (4) they must answer to party leadership; and (5) they often want an answer and not a range of options.

The worst-case scenario that flies in the face of these common "facts" is the academic who reads that a legislative committee is holding a vote on a particular piece of legislation and said academic thinks this is a terrible idea. S/he subsequently fires off a lengthy e-mail the morning of the vote and attaches two academic journal articles. The legislation later passes, and the academic bemoans that legislators do not listen. Not only will this academic be routinely ignored, his/her actions will result in more damage than good because they feed into the negative stereo-type of the academic. Not only did the academic not engage in the policy-making process early enough, s/he did not engage in a conversation, let alone start one off with easy-to-digest, written materials, or respect the legislative process.

To be more effective regional scientists must: (1) know the audience; (2) develop creditability; (3) think long-term; (4) provide a continuous stream of policy work; (5) offer options and not "the answer"; (6) build relationships and partnerships; (7) be sensitive to the timeliness of the research; and (8) use multiple methods of communication. Knowing the audience can be challenging because, like us, some policy makers and staff are very

\footnotetext{
${ }^{4}$ I am often asked in these community settings what I would do. My standard response is "I do not live here, I live in Madison, it's your decision." In addition, what may work in one community may not work in another; the residents of the community are better positioned to make those decisions than an outside expert. In addition, if I as the "expert" tell the community to "do X" and it fails miserably, that creates a negative impression on me as the "expert" and in turn the university. It burns political capital.

${ }^{5}$ If this is not obvious to the reader, recall that many of us make statements like "on the one hand if you implement the policy $\mathrm{X}$ is likely to happen, but on the other hand..."
} 
knowledgeable about particular topics, and fairly ignorant of others. The message must hit just the right chord. Most importantly, policy makers and staff must view the regional scientist as a viable resource, someone approachable, someone who will understand their issues, and someone who will give them honest and open feedback in a nonthreatening manner. This requires information to be shared in easy-to-digest formats (with the understanding that more detailed information is available upon request). The information can never be tied to an "agenda." In other words, the analysis must be viewed as objective so options or alternatives are usually offered. This can at times be a challenge because our research may be definitive and can run against the policy maker's pre-conceived notions. This is why building relationships is vital and must take a long-term perspective. A level of trust must be developed and that requires time. These partnerships or relationships can be with the policy makers directly or with legislative staff, state, regional, and local agencies, nonpartisan policy research organizations (e.g., Wisconsin Legislative Fiscal Bureau), and the news media. The latter is perhaps most effective: when an issue arises or policy options are being discussed, does the local media turn to the regional scientists for comment? Fair and objective comments help build trust amongst the various partners.

A continuous stream of policy work is important to keep your work in the minds of your policy partners. These partners are people too, and names are easily forgotten. A continuous stream of relevant work, especially on issues of the day, makes the regional scientist particularly germane to policy discussions. The timeliness of work is vitally important. ${ }^{6}$ Too often academics are asked if they have research insights on a particular issue, and the response is "I will get a student on that and get back to you in six months." That is too late. In a public policy setting, issues rise and fall very quickly and the ability to respond quickly is key to being relevant. Anticipate them if you can. Often an educated guess is enough to keep engaged in the conversation so the regional scientists remains viewed as relevant, a resource, and helpful. More often than not, a simple conversation brings all the relevant information that is needed into the light. The key is to be responsive and open to a conversation (not a lecture).

Today people receive information in many different formats from traditional print newspapers to twitter. It is important that regional scientists provide a continuous trickle of information to the general public and policy makers. Taking advantage of multiple forms of information dissemination is key. Keep in mind that the information must be in digestible bites and as a continuous drip, not a firehose of information. As people ask for more information we can release the larger flow of the relevant information that we have stored in the form of technical reports and peer-reviewed publications.

\section{CONCLUSIONS}

Is regional science the embodiment of the engaged university? I would say that if we are more strategic in how we approach policy analysis, the answer is a resounding "yes." I believe that regional scientists are drawn to practical problem solving, the types of problems that affect people within their communities. I think we are drawn to bringing rigorous theoretical and

\footnotetext{
${ }^{6}$ Oftentimes I receive a request for information on a particular topic and my knee-jerk reaction is “didn't you see the major study on this very topic I put out six months ago?" Timing is important. When the study or fact sheet based on that study landed on the person's desk, the topic was not relevant and was likely set aside. Six months later it is relevant; given the constant flow of information that study had slipped their mind. A better response is "why yes, I have something that I think is exactly what you need" then resend the study with a smile.
} 
empirical based insights into a range of policy questions. I also think that we want to see our work influence policy thinking. We want to be the embodiment of the engaged university. If we are willing to "go outdoors" and engage the broader community in conversations we can both learn about regional systems and help inform policy. If we keep in mind who the audience is and that we may not have all the answers but rather want to help people make more informed decisions we can become the sharp end of the engaged university spear.

\section{REFERENCES}

Anselin, Luc. (2013) “Andy Isserman's Regional Science," International Regional Science Review, 36, 4-15.

Bridger, Jeffery C. and Theodore R. Alter. (2006) "The Engaged University, Community Development, and Public Scholarship," Journal of Higher Education Outreach and Engagement, 11, 163-178.

Ellison, Julie and Timothy K. Eatman. (2008) Scholarship in Public: Knowledge Creation and Tenure Policy in the Engaged University. Imagining America: Syracuse, NY.

Feser, Edward and Andrew Isserman. (2007) "Special Issue: State Rural Development Policy," Journal of Regional Analysis and Policy, 37, 1-77.

Hirasuna, Donald P. and Susan B. Hansen. (2009) "Is Social Science Research Useful to State Legislators?" International Regional Science Review, 32, 429-444.

Hird, John A. (2009) "The Study and Use of Policy Research in State Legislatures," International Regional Science Review, 32, 523-535.

Isserman, Andrew M. (1993) "Lost In Space? On the History, Status, and Future of Regional Science (Southern Regional Science Association's Presidential Address, April 4, 1992)," Review of Regional Studies, 23, 1-50.

. (1995) "The History, Status, and Future of Regional Science: An American Perspective," International Regional Science Review, 17, 249-296.

. (2010) "A Space Odyssey: The Future is Now What it Used to Be - A Babyboomer's Travel Guide and Challenge to Young Explorers (Southern Regional Science Association's Fellows Address March 26, 2010)," Review of Regional Studies, 40, 135-143.

Lahr, Michael L. (2009) “Regional Science, Regional Scientists, and State Policy," International Regional Science Review, 32, 495-508.

Macke, Don, Donald Hirasuna, Chuck Fluharty, and Martin Shields. (2003) "Regional Scientists Are Talking-Is Anybody Listening?" Journal of Regional Analysis and Policy, 33, 81-97.

Markusen, Ann. (2015) "Problem-driven Research in Regional Science," International Regional Science Review, 38, 3-29.

Mayfield, Loomis. (2001) "Town and Gown in America: Some Historical and Institutional Issues of the Engaged University," Education for Health, 14, 231-240. 
Rickert, Chris. (2015) "All the News Fit to Irritate (Ruling) Anti-Intellectual Republicans," Wisconsin State Journal. Available at:

http:/host.madison.com/news/local/columnists/chris-rickert/chris-rickert-all-the-news-fitto-irritate-ruling-anti/article_292d8021-d29b-5a1e-8851-cedd9796c191.html. 